\title{
HUBUNGAN PENDIDIKAN IBU DAN PARITAS DENGAN PERKEMBANGAN ANAK BALITA UMUR 3-4 TAHUN DI PAUD BAITUL IZZAH KOTA BENGKULU
}

\author{
Arum Kusuma Rini \\ STIKES Tri Mandiri Sakti Bengkulu
}

\begin{abstract}
Mothers Educations, Parity, Early Children Under Five Development. This research aimed to known the relationship of mother and parity education with early children under five development in PAUD Baitul Izzah Bengkulu City. The studied used analytic survey research design. With a Cross Sectional research methods. The population in this studied were all children under five in PAUD Baitul Izzah Bengkulu City that is 28 infants age 3-4 years. Sampling teachnique in this studied used the Total Sampling mean all children under five years, amounted to 28 children. The result obtained from maternal education and pairty relationship with the development of children under five age 3-4 years in PAUD Baitul Izzah Bengkulu that of 28 of children under five there were 10 (35\%) of people who did not good children under five development, or 18 good children under five development, Than 28(100\%) of children there were $3(10,7 \%)$ of the mothers,children under five and secondary education $(89,3 \%)$ of the mothers infants of higher education. And there were 17 infants with parity multiparous mother, and 11(39.9\%) of the mother, children under five parity primipara.
\end{abstract}

Keyword : Mothers Educations, Parity, Early Children Under Five Development

Abstrak: Pendidikan Ibu, Paritas, Perkembangan Anak Balita. Penelitian bertujuan untuk mengetahui hubungan Pendidikan Ibu dan Paritas dengan Perkembangan Anak Balita didi PAUD Baitul Izzah Kota Bengkulu. Metode: dengan metode penelitian Cross Sectional. Populasi dalam penelitian ini adalah seluruh anak balita di PAUD Baitul Izzah Kota Bengkulu yang sebesar 28 anak balita umur 3-4 tahun. Teknik pengambilan sampel menggunakan Total Sampling seluruh anak balita 28 anak. Hasil penelitian: hasil penelitian di dapat dari hubungan pendidikan ibu dan paritas dengan perkembangan anak balita umur 3-4 tahun di PAUD Baitul Izzah Kota Bengkulu bahwa dari $28 \%$ anak balita terdapat $35 \%$ orang balita perkembangan yang tidak baik, atau 18 orang perkembangan yang baik: dari 28 orang anak terdapat $3(10,7 \%)$ orang ibu yang pendidikannya menengah dan $25(89 \%)$ orang ibu pendidikan tinggi. Dan terdapat 17 orang ibu dengan paritas multipara dan $11(39,3 \%)$ orang paritas primipara.

Kata Kunci : Pendidikan Ibu, Paritas, Perkembangan Anak Balita

\section{PENDAHULUAN}

Anak merupakan generasi penerus bangsa yang berkualitas, oleh karena itu kita mengharapkan agar anak dapat tumbuh dan kembang secara fisik, sosial, dan mental. Anak dengan rentan kehidupannya mengalami tahap perkembangan meliputi fisik, kognitif, 
moral, emosi, dan sosial. Perkembangan yang tidak sosial mengakibatkan gangguan perkembangan, sehingga menghambat potensi sumber daya manusia.

Berdasarkan Dinas Pendidikan Nasional Kota Bengkulu sebanyak 447 PAUD, dari 447 PAUD Baitul Izzah merupakan PAUD dengan jumlah anak PAUD yang paling banyak. Jumlah anak PAUD Baitul Izzah Kota bengkulu berjumlah 28 orang yang terdiri dari anak laki-laki sebanyak 11 orang dan anak perempuan sebanyak 17 orang. Peneliti melakukan wawancara kepada gurunya dari hasil wawancara tersebut ditemukan 10 orang anak balita berumur 3-4 tahun yang dijadikan sampel penelitian awal 7 anak diantaranya belum bisa menguasai beberapa keterampilan seperti menulis, menggambar lingkaran, mewarnai gambar, bahkan belum bisa mengingat nama orang tua, yang seharusnya anak 3-4 tahun itu semuanya itu sudah dapat melakukan dengan baik. Dari 7 responden yang mengalami permasalahan keterlambatan dalam meguasai keterampilan, terdapat 4 orang ibu dengan jenjang pendidikan SMA, dan 5 ibu berpendidikan D3, Akademi sederajat. Begitu juga dengan paritas yang dialami oleh seorang ibu diantaranya, terdapat 6 orang anak yang mengalami jarak kelahiran yang terlalu berdekatan sehingga kurangnya perhatiannya orang tua terhadap anak tersebut hal ini terlihat dari wawancara gurunya mengatakan bahwa orang tuanya lebih sibuk bekerja diluar rumah dibandingkan berada dirumah.

Bukti lain dari penelitian sebelumnya bahwa pendidikan ibu merupakan faktor yang paling penting dalam kesehatan anak. Pendidikan mempunyai peranan yang sangat menentukan bagi perkembangan anak. Pendidikan orang tua tersebut berpengaruh dalam mendidik anak agar dapat mencapai tujuan yang diharapkan dengan mengantar anak pada tahapan perkembangan sesuai dengan pertambahan usia dan tugas perkembangannya secara optimal dan utuh (Apriastuti, 2013).

Berdasarkan latar belakang diatas maka peneliti ini ingin lebih lanjut tentang anak-anak yang perkembangan tidak tercapai sesuai dengan perkembangan yang normal sesuai dengan usianya.

Perkembangan motorik anak terbagi menjadi dua bagian yaitu motorik kasar dan motorik halus. Motorik kasar terbentuk saat anak mulai memiliki keseimbangan dan juga koordinasi yang hampir mirip dengan orang dewasa. Motorik kasar merupakan kemampuan yang membutuhkan koordinasi sebagian besar dari tubuh anak. Untuk dapat merangsang motorik kasar, anak dapat dilakukan dengan melatih anak untuk meloncat, memanjat, berlari, berjinjit, dan berjalan (Iswantiningtyas \& Wijaya, 2015).

\section{METODE PENELITIAN}

Desain penelitian dalam penelitian ini adalah survei analitik dengan rancangan cross sectional . subjek penelitian ini adalah balita umur 3-4 tahun sebanyak 28 anak di PAUD Baitul Izzah yang dilaksanakan pada tanggal $19 \quad-24$ agustus tahun 2013. Subyek penelitian ini dipilih dengan Total Sampling yang artinya penelitian yang megambil semua anak balita 3-4 tahun. Setelah data terkumpul, maka analisa data dan selanjutnya dilakukan uji statistik menggunakan uji chi-square. 
HASIL PENELITIAN

Data Umum

Tabel 1

Distribusi frekuensi Pendidikan Ibu di PAUD Baitul Izzah Kota Bengkulu

No Pendidikan Ibu $\quad$ Frekuensi \%

\begin{tabular}{cccc}
\hline 1 & Menengah & 3 & 10,7 \\
\hline 2 & Tinggi & 25 & 89,3 \\
\hline
\end{tabular}

Dari tabel 1 menunjukkan bahwa dari 28 sampel $(100 \%)$ terdapat 3 orang ibu balita $(10,7 \%)$ pendidikan menengah dan 25 orang balita (89\%) pendidikan tinggi.

\section{Tabel 2}

Distribusi Frekuensi Paritas di PAUD Baitul Izzah Kota Bengkulu

\begin{tabular}{ccccc}
\hline & No & Paritas & Frekuensi & $\%$ \\
\hline 1 & Multipara & 17 & 60,7 \\
\hline 2 & Primipara & 11 & 39,3 \\
\hline
\end{tabular}

Dari tabel 2 menunjukkan bahwa dari 28 sampel $(100 \%)$ terdapat 17 orang balita $(60,7 \%)$ orang balita $(64,3 \%)$ dengan paritas multipara, dan 11 orang ibu balita $(39,3 \%)$ paritas primipara.

Tabel 3

Distribusi Frekuensi Perkembangan Anak Balita di PAUD Baitul Izzah Kota Bengkulu

\begin{tabular}{cccc}
\hline No & Perkembangan Anak Balita & Frekuensi & $\%$ \\
\hline 1 & Tidak Baik & 10 & 35,7 \\
\hline 2 & Baik & 18 & 64,3 \\
\hline
\end{tabular}

Dari tabel 3 menunjukkan bahwa dari 28 sampel $(100 \%)$ terdapat 10 orang balita $(35,7 \%)$ perkembangan tidak baik, dan 18 orang balita $(64,3 \%)$ perkembangan baik.

Berdasarkan hasil uji statistik statistik dengan menggunakan uji Chi square didapatkan $.003^{\mathrm{b}}$ dengan nilai exact.sig (p) 1,000. Karena nilai $p>\alpha$
0,05, maka Ho ditrima dan Ha ditolak. Jadi tidak ada hubungan yang signifikan antara paritas ibu dengan perkembangan anak balita.

\section{Tabel 4}

Hubungan Pendidikan Ibu dengan Perkembangan Anak Balita di PAUD Baitul Izzah Kota Bengkulu

\begin{tabular}{|c|c|c|c|c|c|}
\hline \multirow{3}{*}{$\begin{array}{l}\text { Pendidika } \\
\text { n Ibu }\end{array}$} & \multicolumn{2}{|c|}{$\begin{array}{l}\text { Perkembanga } \\
\text { n Anak Balita }\end{array}$} & \multirow{2}{*}{$\begin{array}{c}\text { Tota } \\
1\end{array}$} & \multirow{2}{*}{$\chi^{2}$} & \multirow{2}{*}{$\mathrm{P}$} \\
\hline & $\begin{array}{c}\text { Tidak } \\
\text { Baik }\end{array}$ & Baik & & & \\
\hline & $\mathrm{N}$ & $\mathrm{N}$ & $\mathrm{N}$ & \multirow{4}{*}{$\begin{array}{c}1.402 \\
b\end{array}$} & \multirow{4}{*}{$\begin{array}{c}0,28 \\
4\end{array}$} \\
\hline Menengah & 2 & 1 & 3 & & \\
\hline Tinggi & 8 & 17 & 25 & & \\
\hline Total & 10 & 18 & 28 & & \\
\hline
\end{tabular}
dari 3 orang ibu balita yang pendidikan menengah terdapat 2 orang balita perkembangan baik, dari 25 orang balita pendidikan tinggi terdapat 8 orang balita perkembangan tidak baik, dan 17 orang balita perkembangan baik. Dari hasil uji didapatkan sebesar $1.402^{\mathrm{b}}$ dengan nilai asymp. $\operatorname{sig}(\mathrm{p})=.236$. karena nilai $\rho=$ $0,284>\alpha 0,05$ maka Ho diterima dan $\mathrm{Ha}$ ditolak. Jadi tidak ada hubungan yang sigifikan antara pendidikan ibu dan paritas dengan perkembangan anak balita.

\section{Tabel 5}

Hubungan Paritas dengan

Perkembangan Anak Balita di PAUD Baitul Izzah Kota Bengkulu

\begin{tabular}{llll}
\multirow{2}{*}{ Paritas } & \multicolumn{2}{l}{ Perkembangan } \\
& $\begin{array}{l}\text { Anak Balita } \\
\text { Tidak Baik Total } \\
\text { Baik }\end{array}$ & & \\
& & & \\
\end{tabular}

\begin{tabular}{cccc}
\hline Multipara & 6 & 11 & 17 \\
\hline Primipara & 4 & 7 & 11 \\
\hline Total & 10 & 18 & 28 \\
\hline \multicolumn{5}{c}{003} & 1,000 \\
\hline Dari & tabel diatas & diketahui bahwa
\end{tabular}
dari 17 orang ibu balita paritas multipara terdapat 6 orang balita perkembangan tidak 
baik, dan 11 orang balita perkembangan baik, dari 11 orang ibu paritas primipara terdapat 4 orang balita perkembangan tidak baik, 7 orang balita perkembangan baik. Dari hasil uji chi -square (Pearson Chisquare) didapatkan sebesar $.003^{\mathrm{b}}$ dengan nilai exact.sig (p) 1,000. Karena nilai $\mathrm{p}>\alpha$ 0,05 maka Ho diterima dan Ha ditolak. Jadi tidak ada hubungan yang signifikan antara paritas ibu dengan perkembangan anak balita.

Hasil penelitian menunjukkan bahwa dari 28 orang ibu balita terdapat 17 orang ibu balita $(60,7 \%)$ dengan paritas multipara, dan 11 orang ibu balita $(39,3 \%)$ paritas primipara. Secara umum faktor yang berhubungan dengan perkembangan anak adalah pendidikan orang tua, jumlah saudara atau paritas. Jarak kelahiran yang pendek seringkali menyebabkan gangguan tumbuh kembang pada anak karena anak terlalu cepat di sapih dari ASI(Air Susu Ibu), tidak sempat lagi untuk menyiapkan makanan khusus untuk anaknya dan perhatian serta kasih sayang ibu juga akan berkurang karena ibu berkonsentrasi pada kehamilannya. Kecerdasan anak juga akan lebih rendah sebab kurangnya stimulasi mental dari ibu (Schandy, 2011).

Hasil penelitian menunjukkan bahwa dari 28 sampel (100\%) terdapat 10 orang balita $(35,7 \%)$ perkembangan tidak baik, hal ini terlihat dari tidak bisa memakai sepatu sendiri, tidak bisa mencuci tangan sesudah makan, belum bisa memakai baju kemeja dengan bantuan, belum bisa menyebutkan harihari dalam satu minggu, dan 18 orang balita $(64,3 \%)$ perkembangan baik hal ini terlihat anak balita sudah bisa menyebutkan nama-nama binatang, sudah bisa mengenal 4 warna dan dapat mencontoh menggambar lingkaran pada kertas kosong. Perkembangan motorik harus mulai memiliki kemampuan menggoyangkan jari-jari kaki menggambar dua atau tiga bagian memilih garis yang lebih panjang dan menggambar orang, melepas objek dengan garis lurus, bermain, menempatkan objek kedalam wadah, makan sendiri, minum dari cangkir dengan bantuan menggunakan sendok dan dengan bantuan makan dengan jari, membut coretan diatas kertas. Pada perkembangan bahasa diawali mampu menyebutkan satu hingga empat warna, menyebutkan kegunaan benda, menghitung, mengartikan dua kata, dua kata depan, mengerti dua sifat. Menggunakan bunyi untuk mengidentifikasi Objek, orang dan aktivitas, menirukan berbagai bunyi kata, memahami arti larangan, merespon terhadap panggilan dan orang-orang-orang anggota keluarga terdekat. Di usia 3-4 tahun, anak sangat suka menggerakkan tubuhnya untuk menunjukkan kegembiraannya. Senang melompat, merangkak, mendaki, melempar, menangkap, atau menendang dengan kuat. Anak usia ini sedang mengalami perkembangan motorik yang sangat pesat dan mengaggumkan (Iswantiningtyas dan wijaya, 2015).

Berdasarkan hasil bivariat menunjukkan bahwa tidak ada hubungan antara pendidikan ibu dengan perkembangan anak balita semakin baik. Dari 25 orang ibu balita pendidikan tinggi terdapat 8 orang balita perkembangan tidak baik, hal ini terlihat dari anak balita yang belum bisa memakai sepatu sendiri, belum bisa memakai kemeja sendiri, belum bisa menggambar segiempat dan segitiga. Dapat dijelaskan bahwa perkembangan anak balita tidak hanya berhubungan dengan pendidikan ibu tetapi ada factor lain yang berhubungan dengan 
perkembangan anak balita diantaranya seperti faktor fisik (cuaca, sanitasi, keadaan rumah, radiasi) dan faktor lainnya. Hasil penelitian menunjukkan bahwa dari 3 orang ibu balita yang pendidikan menengah terdapat 1 orang balita perkembangan baik hal yang terlihat dari anak balita yang bisa memakai sepatu sendiri, bisa memakai kemeja sendiri, bisa menggambar segi empat dan segitiga( Schandy, 2011)

Dari hasil uji chi-square ( Fisher Exact Test) didapatkan nilai $\mathrm{p}=0,284>\alpha 0,05$, maka Ho diterima dan Ha ditolak. Jadi tidak ada hubungan yang signifikan antara pendidikan ibu dengan perkembangan anak balita.

Analisis Bivariat Menunjukkan bahwa tidak ada hubungan yang signifikan antara paritas dengan perkembangan anak balita di PAUD Baitul Izzah Kota Bengkulu. Seharusya semakin jumlah kelahirannya sedikit maka akan semakin baik perkembangannya pada anak balita. Tetapi karena tidak ada hubungan signifikan, semakin sedikit jumlah kelahirannya maka belum tentu akan berdampak pada semakin baiknya perkembangan anak balita itu sendiri. Hal ini terlihat dari 11 orang ibu balita yang jumlah kelahirannya sedikit terdapat 4 orang balita yang mengalami perkembangan tidak baik. Hal ini terlihat anak balita tidak dapat menyebutkan harihari dalam seminggu. Tidak dapat mencontoh membuat lingkaran pada kertas kosong. Dijelaskan bahwa perkembangan anak balita tidak hanya berhubungan dengan paritas dengan primipara dan multipara, tetapi ada faktor lain yang berhubungan dengan perkembangan anak diantaranya seperti faktor genetik (berbagai faktor bawaan yang normal, jenis kelamin).
Hasil penelitian dari 17 orang ibu balita paritas multipara terdapat 11 orang balita perkembangan baik hal ini terlihat dari anak balitaa bisa memakai sepatu sendiri, cuci tangan sesudah makan, memakai baju kemeja dengan bantuan, , dari 11 orang ibu paritas primipara terdapat 4 orang balita perkembangan tidak baik. Berdasarkan penelitian Iswantiningtyas \& wijaya 2015, mengatakan bahwa ada usia ini ketrampilan motorik hausnya juga semakin berkembang. Sudah bisa membuat coretan dengan pensil mengikat tali sepatu, mengancing baju kemeja (Schady, 2011)

Jadi berdasarkan penjelasan diatas diketahui bahwa tidak ada hubungan yang signifikan antara paritas dengan perkembangan anak. Hal ini disebabkan karena adanya faktor lain yang mempengaruhinya. Faktor lain adalah gizinya pada waktu hamil, faktor bawaan dari orang tuanya.

Dari hasil uji Chi-Square (fisher's Exact test) didapatkan nilai $\mathrm{p} 1,000>\alpha \quad 0,05$, maka Ho diterima dan Ha ditolak. Jadi berdasarkan penjelasan diatas diketahui bahwa tidak ada hubungan yang signifikan antara paritas dengan perkembangan anak balita.

\section{KESIMPULAN DAN SARAN}

Hasil penelitian menunjukkan bahwa perkembangan anak usia 3-4 tahun dari 28 orang ibu balita, terdapat 3 orang ibu balita $(10,7 \%)$ pendidikan menengah dan 25 orang ibu balita $(89 \%)$ pendidikan tinggi, 17 orang ibu balita $(60,7 \%)$ dengan paritas multipara, 11 orang ibu balita $(39,3 \%)$ paritas primipara. Dari 28 anak balita terdapat 10 orang balita $(35,7 \%)$ perkembangan tidak baik, dan 18 orang balita $(64,3 \%)$ 
perkembangan baik. Bagi masyarakat untuk dapat mengetahui tentang gangguan perkembangan pada anak balita umur 3-4 tahun. Diharapkan meningkatkan pendidikan kesehatan dan perkembangan anak balita. Mengetahui bahan bacaan, sumber pustaka tentang mengetahui hubungan pendidikan ibu dan paritas dengan perkembangan anak balita umur 34 tahun. Dan diharapkan dapat menjadi masukan dalam yang bermanfat bagi peneliti selanjutnya sehingga peneliti selanjutnya dapat melakukan penelitian dengan variabel yang berbedah dan lebih beragam serta dengan metode lainnya.

\section{DAFTAR RUJUKAN}

Apriastuti, D. A (2013). Analisis Tingkat Pendidikan dan Pola Asuh Orang Tua dengan Perkembangan Anak Usia 48 - 60 Bulan. Jurnal Ilmiah Kebidanan. 4 (1)

Felfe, C. \& Hsin, A (2012). Maternal work conditions and child development. Economics of Education Review. 31, 1037- 1057

Iswantiningtyas V \& Wijaya I (2015). Meningkatkan Kemampuan Motorik Kasar Anak Usia Dini Melalui Permainan Tradisional Gobak Sodor. Jurnal Vinus. 1(3)

Schady N (2011). Parents' Education, Mothers' Vocabulary, and Cognitive Development in Early Childhood: Longitudinal Evidence From Ecuador. Am J Public Health. 2299-2307. doi:10.2105/AJPH.2011.300253.

Wang C. (2013). Maternal Education and Micro-Geographic Disparities in Nutritional Status among SchoolAged Children in Rural Northwestern China. Plos One. 8
(12), www.plosone.org (diperoleh 15 April 2017).

Zhang X. (2012). The Effect of Parental Education and Family Income on Mother-Child Relationships, Father-Child Relationship, and Family Environments in The People's Republic of Cina. Fam Proc. 51, 483-497. www.FamilyProcess.org (diperoleh 15 April 2017). 